\title{
Prevalence of antimicrobial-resistant Streptococcus species among respiratory patients and meat products, and antibacterial effects of oregano oil nanoemulsion
}

\author{
Alshimaa A. Hassanien ${ }^{1}$ (ID) and Nahed Mahmoud Abdel-Aziz² (D)
}

\author{
1. Department of Zoonoses, Faculty of Veterinary Medicine, Sohag University, Sohag, Egypt; 2. Department of \\ Food Hygiene, Faculty of Veterinary Medicine, Sohag University, Sohag, Egypt. \\ Corresponding author: Alshimaa A. Hassanien. e-mail: alshaimaa@vet.sohag.edu.eg \\ Co-author: NMA: nahedvet2012@yahoo.com \\ Received: 10-02-2021, Accepted: 27-04-2021, Published online: 24-06-2021
}

doi: www.doi.org/10.14202/IJOH.2021.135-141 How to cite this article: Hassanien AA, Abdel-Aziz NM (2021) Prevalence of antimicrobial-resistant Streptococcus species among respiratory patients and meat products, and antibacterial effects of oregano oil nanoemulsion, Int. J. One Health, 7(1): 135-141.

\begin{abstract}
Background and Aim: Antimicrobial-resistant Streptococcus species causes several diseases in humans with infection recurrence in some cases. Handling of food under unhygienic conditions resulted in transmission of pathogens to food leading to risks for consumers' health. This work studies the possible role of humans in transmission of human pathogens to food products. In this study, we focused on the presence of antimicrobial resistance Streptococcus pyogenes, Streptococcus mitis, and Streptococcus pneumoniae found in respiratory patients and in some meat products. We detected the risk factors for patient's infection and examined the antibacterial effect of oregano oil nanoemulsion (ONE) at different concentrations against the multi-drug resistance strains of streptococci.
\end{abstract}

Materials and Methods: Microbiological culture and polymerase chain reaction were used to identify $S$. pyogenes, S. mitis, and S. pneumoniae in 120 throat swab samples and 200 meat products. The disk diffusion method was used for investigating the prevalence of resistance against 10 antimicrobials that are commonly used in the treatment of humans and animals. ONE at four concentrations $(0.5 \%, 1.0 \%, 2.0 \%$, and $3.0 \%)$ with an average particle size of $45.4 \mathrm{~nm}$ was identified using transmission electron microscopy. The effect of ONE on Streptococcus species isolates was examined using the well diffusion method. Risk factors for human infection were detected using statistical analysis.

Results: S. pyogenes, S. mitis, and S. pneumoniae were detected in $14(11.7 \%), 9(7.5 \%)$, and 7 (5.8\%), respectively, of 120 throat swabs of patients. These bacteria were also detected in $11(5.5 \%), 8(4 \%)$, and $6(3 \%)$, respectively, of 200 meat products samples. Beef luncheon had the highest infection rate for the three species of streptococci. The majority of these isolates showed resistance to antimicrobials such as tetracycline and amoxicillin/clavulanic acid. ONE had an inhibitory effect on the growth of $S$. pyogenes, $S$. mitis, and $S$. pneumoniae, and its effect was significantly increased at a high concentration $(3 \%)$, with a mean inhibition zone of $36.45 \pm 0.302 \mathrm{~mm}$. Very young and old patients, those with chronic diseases, and those exposed to the infection several times were most susceptible to infection.

Conclusion: ONE may be used as a therapeutic agent at safe and specific doses, and also in the food industry, to prevent the spoilage of food and protect human health.

Keywords: meat products, Oregano oil nanoemulsion, Streptococcus pneumoniae, Streptococcus mitis, Streptococcus pyogenes.

\section{Introduction}

Streptococcus species originate from several natural sources, including humans and many animal species, in which they naturally colonize the nasal passage, pharynx, and mucosal surfaces of the mouth and intestinal tract. Streptococcus pyogenes colonizes the skin and throat of humans, and causes several diseases, ranging from mild infections such as tonsillitis, pharyngitis, and impetigo, to severe invasive infections such as septicemia, necrotizing fasciitis, and streptococcal toxic shock syndrome [1]. Streptococcus mitis commensally inhabit

Copyright: Hassanien and Abdel-Aziz. This article is an open access article distributed under the terms of the Creative Commons Attribution 4.0 International License (http://creativecommons.org/ licenses/ by/4.0/), which permits unrestricted use, distribution, and reproduction in any medium, provided you give appropriate credit to the original author(s) and the source, provide a link to the Creative Commons license, and indicate if changes were made. The Creative Commons Public Domain Dedication waiver (http:// creativecommons.org/ publicdomain/zero/1.0/) applies to the data made available in this article, unless otherwise stated. the human oral cavity [2]. Although $S$. mitis is considered to have low pathogenicity, it is associated with serious clinical conditions, such as sepsis, pancreatic diseases, and endocarditis, especially in patients with impaired immunity [3]. Streptococcus pneumoniae colonies the human nasopharynx and oropharynx, and is responsible for several human infections, including otitis media, bronchitis, bacteremia, pneumonia, septicemia, septic arthritis, endocarditis, cellulitis, osteomyelitis, peritonitis, and meningitis [4,5].

The poor hygiene leads to contamination of food during handling and preparation through coughing, sneezing, or from skin lesions, from people infected with human pathogens [6]. Prevention of such contamination is important, particularly in S. pyogenes, since the carriers of this pathogen may be asymptomatic [7].

Streptococci are identified by their morphological characteristics, biochemically, and serologically. Recently, molecular methods for the identification of 
these species have been developed. The species-specific primer spy1258, used to identify S. pyogenes, is important for the study of the epidemiology, pathogenesis, and treatment of this pathogen [8]. Molecular methods are able to discriminate between $S$. mitis and $S$. pneumoniae, which have similar biochemical and immunological characteristics [9]. The sequence of the pheA gene can be used to differentiate $S$. mitis from other members of the viridans Streptococcal group, and is markedly different from the sequence of the gene in S. pneumoniae [10]. The sequence of the Spn9802 gene of $S$. pneumoniae is specific to $S$. pneumoniae and does not exhibit cross-reactivity with other species [11].

The acquisition of antimicrobial resistance by streptococci increases their pathogenicity in humans and animals, and causes disease recurrence [12]. Essential oils can be used as antimicrobial agents, but direct application of such oils is limited, because they have poor solubility in water, and therefore must be present in large amounts to produce an effect. The use of large amounts of essential oils may negatively affect food flavor. Therefore, encapsulation of oils as nanoemulsions should enhance their stability, bioefficacy, and bioavailability [13]. Oregano oil nanoemulsion (ONE) has been used as a green bactericidal agent against pathogens resistant to antimicrobial agents. ONE is also used as an antioxidant, antibiofilm, and anti-inflammatory agent in drug delivery systems and skincare medications. In the food industry, it is used as a food preservative to improve its shelf life [14].

This work illuminates the role of humans in the contamination of food products by human pathogens. In this study, we focused on the presence of three pathogenic streptococci found in patients with upper respiratory infections and in some meat products. We detected their antimicrobial responses and the risk factors for infection. We also explored the role of ONE as a natural antibacterial against drug-resistant strains of streptococci.

\section{Materials and Methods}

\section{Ethical approval and Informed consent}

This approval was obtained from Ethics Committee of Sohag University Hospital. Patients' participation and collection of samples were done after their consent or their guardian's consent.

\section{Study period and location}

This study was conducted from December 2019 to January 2021 in Sohag city which is located in Sohag Governorate in Upper Egypt. All samples were processed for bacteriological examination in the laboratory of Food Hygiene Department, Faculty of Veterinary Medicine, Sohag University.

\section{Study design}

Samples from humans, beef luncheon, basterma, beef burger and beef kofta were examined for the presence of S. pyogenes, S. mitis, and S. pneumoniae using bacteriological examination, followed by polymerase chain reaction (PCR), based on the detection of genes specific for each species. All isolates of the three species identified in human and meat products were examined for their resistance against 10 antimicrobials which are generally used in human and veterinary therapeutics using the disk diffusion method. Then, the isolates were exposed to ONE at different concentrations to study its effect, using the well diffusion method. Data were collected from patients, to identify factors related to their infection.

\section{Collection of samples}

One hundred and twenty throat swabs were collected from patients admitted to Sohag University Hospital with upper respiratory tract infections such as tonsillitis and pharyngitis. Two hundred samples of meat products, including 50 samples of each of ready-to-eat beef luncheon and basterma, and frozen beef burger and beef kofta were purchased from different markets and groceries in Sohag city.All samples were transported directly to the laboratory for bacteriological examination. A standard form was used for collection of patient data with respect to age, gender, medical, and infection history.

\section{Microbiological examination of samples}

Meat samples were prepared as previously described [15]. Human and meat samples were incubated in azide dextrose broth (HiMedia, India) for $24 \mathrm{~h}$ at $37^{\circ} \mathrm{C}$. Then, samples were cultured on selective Streptococcus agar (Becton Dickinson) containing sheep blood. The colonies were examined by Gram staining and biochemical tests such as catalase, urease, haemolysis, motility, and sugar fermentation like arabinose, fructose, glucose, lactose and mannitol [16].

\section{Molecular identification of Streptococcus species}

DNA was extracted from the suspected pathogenic isolates of human and meat products using QIAamp DNA Mini Kits (Qiagen, Hilden, Germany). PCR was used for the detection of the spy 1258 gene specific for $S$. pyogenes, using the primer sequences F: AAAGACCGCCTTAACCACCT and R: TGGCAAGGTAAACTTCTAAAGCA with $407 \mathrm{bp}$ [17], the pheA gene specific for $S$. mitis, with the primer sequences F: TGGCTTATC CTTCCTAGATGG and R: GATTGCGGTCGACAA A with $557 \mathrm{bp}$ [10], and the spn9802 gene, specific for $S$. pneumoniae, with the primer sequence F: CAA GTC GTT CCA AGG TAA CAA GTC T and R: CTA AAC CAA CTC GAC CAC CTC TTT (Metabion, Germany) with 162 bp [18], using a thermal cycler (Bio-Rad, Hercules, CA) from Applied Biosystems (Foster City, CA). Some modifications in the cycling conditions of the PCR were made, as follows: For the spy 1258 gene, $2 \mathrm{~min}$ at $94^{\circ} \mathrm{C}$, followed by 30 cycles at $94^{\circ} \mathrm{C}$ for $30 \mathrm{~s}, 56^{\circ} \mathrm{C}$ for $30 \mathrm{~s}$, and $72^{\circ} \mathrm{C}$ for $1 \mathrm{~min}$, and then a final extension for $5 \mathrm{~min}$ at $72^{\circ} \mathrm{C}$. The pheA gene regime was $5 \mathrm{~min}$ at $94^{\circ} \mathrm{C}, 30$ cycles at $94^{\circ} \mathrm{C}$ for $30 \mathrm{~s}, 58^{\circ} \mathrm{C}$ for $1 \mathrm{~min}$, and $72^{\circ} \mathrm{C}$ for $45 \mathrm{~s}$, and then $10 \mathrm{~min}$ at $72^{\circ} \mathrm{C}$. The spn 9802 gene regime was $2 \mathrm{~min}$ at 
$94^{\circ} \mathrm{C}$, followed by 25 cycles at $94^{\circ} \mathrm{C}$ for $15 \mathrm{~s}, 57^{\circ} \mathrm{C}$ for $15 \mathrm{~s}, 72^{\circ} \mathrm{C}$ for $1 \mathrm{~min}$, and a final extension for $5 \mathrm{~min}$ at $72^{\circ} \mathrm{C}$. The products were examined using $1 \%$ agarose gel electrophoresis with ethidium bromide and visualized using a light transilluminator from Biometra (Analytik Jena Group, Jena, Germany).

\section{Antimicrobial sensitivity tests}

The disk diffusion method was performed using Müeller-Hinton agar using antimicrobial discs from Oxid Corporation, UK, according to Quinn et al. [16]. The strains of streptococci isolated were tested against 10 antimicrobials from several groups. The zones of inhibition were measured, and the results interpreted based on Clinical and Laboratory Standards Institute [19] guidelines.

\section{Preparation and characterization of ONE}

Oregano oil and Tween 80 were mixed at a 2:1 ratio, dissolved in deionized water, and mixed using a magnetic stirrer (Dai Han, Seoul, Korea) for $10 \mathrm{~min}$. The resulting emulsion was sonicated using an ultrasonic homogenizer [20]. Nanoemulsion was prepared in the Nanotechnology Research Unit, Animal Health Research Institute, Cairo, Egypt. The size of the nanoemulsion particles was measured using transmission electron microscopy in the Electron Microscopy Unit, Assiut University.

\section{Effects of ONE}

Streptococcus isolates were cultured in selective Streptococcus agar medium for $24 \mathrm{~h}$ at $37^{\circ} \mathrm{C}$, then $1 \times 10^{6}$ $\mathrm{CFU} / \mathrm{mL}$ were streaked on Müeller-Hinton agar containing nanoemulsion at concentrations of $0.5 \%, 1.0 \%$, $2.0 \%$, and $3.0 \%$, using the well diffusion method with $50 \mu \mathrm{l}$ in each well. The effect of the nanoemulsion was measured by the growth of the inhibition zone [21].

\section{Statistical analysis}

The effect of ONE was reported as mean and standard error, calculated using SPSS 14. Pearson correlation was used for detecting the risk factors for infection. The threshold for identification of significant differences was set to $\mathrm{p}<0.05$.

\section{Results}

Among 120 patients with a respiratory infection, S. pyogenes was present in $14(11.7 \%), S$. mitis in $9(7.5 \%)$, and S. pneumoniae in 7 (5.8\%) (Table-1). Factors associated with infection were increased in elderly and young patients, those with chronic diseases, and subjects infected more than 1 time (Table-2). S. pyogenes had the highest prevalence $(5.5 \%)$ in the meat products examined, followed by S. mitis (4\%) and S. pneumoniae $(3 \%)$. Beef luncheon harbored the highest infection rate of all the examined streptococci, in which $S$. pyogenes

Table-1: Incidence of Streptococcus species in respiratory patients' samples.

\begin{tabular}{|c|c|c|c|c|c|c|c|}
\hline \multirow[t]{2}{*}{ Samples } & \multirow{2}{*}{$\begin{array}{l}\text { No. of examined } \\
\text { samples }\end{array}$} & \multicolumn{2}{|c|}{ Streptococcus pyogenes } & \multicolumn{2}{|c|}{ Streptococcus mitis } & \multicolumn{2}{|c|}{ Streptococcus pneumoniae } \\
\hline & & $\mathbf{n}$ & $\%$ & $\mathbf{n}$ & $\%$ & $\mathbf{n}$ & $\%$ \\
\hline Throat swabs & 120 & 14 & 11.7 & 9 & 7.5 & 7 & 5.8 \\
\hline
\end{tabular}

Table-2: Characteristics of respiratory patients infected with Streptococcus species.

\begin{tabular}{|c|c|c|c|c|c|c|c|}
\hline \multirow[t]{2}{*}{ Risk factors } & \multicolumn{2}{|c|}{$\begin{array}{c}\text { Streptococcus } \\
\text { pyogenes } n=14\end{array}$} & \multicolumn{2}{|c|}{$\begin{array}{c}\text { Streptococcus } \\
\text { mitis } \mathrm{n}=9\end{array}$} & \multicolumn{2}{|c|}{$\begin{array}{c}\text { Streptococcus } \\
\text { pneumoniae } n=7\end{array}$} & \multirow[t]{2}{*}{ p-value } \\
\hline & n & $\%$ & $\mathbf{n}$ & $\%$ & $\mathbf{n}$ & $\%$ & \\
\hline Age & & & & & & & 0.656 \\
\hline $5-11$ & 7 & 50 & 2 & 22.2 & 2 & 28.6 & \\
\hline $12-19$ & 3 & 21.4 & 2 & 22.2 & 0 & 0 & \\
\hline $20-30$ & 0 & 0 & 1 & 11.1 & 0 & 0 & \\
\hline $31-40$ & 0 & 0 & 1 & 11.1 & 1 & 14.3 & \\
\hline $41-50$ & 2 & 14.3 & 1 & 11.1 & 3 & 42.9 & \\
\hline$>50$ & 2 & 14.3 & 2 & 22.2 & 1 & 14.3 & \\
\hline Gender & & & & & & & 0.345 \\
\hline Female & 5 & 35.7 & 6 & 66.7 & 3 & 42.9 & \\
\hline Male & 9 & 64.3 & 3 & 33.3 & 4 & 57.1 & \\
\hline Medical history* & & & & & & & 0.05 \\
\hline COPD & 3 & 21.4 & 1 & 11.1 & 5 & 71.4 & \\
\hline Diabetes mellitus & 6 & 42.9 & 3 & 33.3 & 4 & 57.1 & \\
\hline Bronchial asthma & 4 & 28.6 & 2 & 22.2 & 3 & 42.9 & \\
\hline Liver diseases & 2 & 14.3 & 0 & 0 & 0 & 0 & \\
\hline Heart diseases & 3 & 21.4 & 2 & 22.2 & 3 & 42.9 & \\
\hline Renal diseases & 1 & 7.14 & 0 & 0 & 2 & 28.6 & \\
\hline Rheumatic heart disease & 2 & 14.3 & 2 & 22.2 & 1 & 14.3 & \\
\hline History of infection & & & & & & & 0.05 \\
\hline $1^{\text {st }}$ time & 1 & 7.14 & 2 & 44.4 & 2 & 28.6 & \\
\hline $2^{\text {nd }}$ time & 2 & 14.3 & 3 & 33.3 & 1 & 14.3 & \\
\hline $3^{\text {rd }}$ time & 3 & 21.4 & 1 & 11.1 & 1 & 14.3 & \\
\hline More than 3 times & 8 & 57.1 & 3 & 33.3 & 3 & 42.9 & \\
\hline
\end{tabular}

*Patients have more than 1 disease 
was present in $12 \%, S$. mitis in $8 \%$, and $S$. pneumoniae in $6 \%$ of samples. All three streptococci were detected in all meat products, except for $S$. pneumoniae which could not be detected in beef kofta (Table-3). The majority of the strains of streptococci isolated from both human and meat products were resistant to more than 1 antimicrobial agent, such as tetracycline and amoxicillin/clavulanic acid, which had the highest prevalence of resistance (Table-4). ONE at concentrations of $0.5 \%, 1 \%, 2 \%$, and $3 \%$ had an inhibitory effect on the growth of Streptococcus isolates, with mean inhibition zones of $14.84 \pm 0.309,30.07 \pm 0.425$, $31.29 \pm 0.450$, and $36.45 \pm 0.302 \mathrm{~mm}$, respectively. The inhibitory effect of ONE increased significantly with concentration (Table-5).

\section{Discussion}

Among 120 throat swabs taken from patients with upper respiratory infection, the presence of $S$. pyogenes was investigated in $14(11.7 \%)$ patients using a spy 1258 gene-specific primer. Dunne et al. [22], Al-Saadi et al. [23], and Khalaf et al. [24] reported $S$. pyogenes at rates of $18.9 \%, 6.7 \%$, and $4.3 \%$, respectively. $S$. mitis was detected in $9(7.5 \%)$ patients, using the species-specific pheA gene, and S. pneumoniae was identified in 7 (5.8\%) patients, using the spn9802 gene (Table-1, Figure-1-3). Higher results were obtained by Thornton et al. [25] and Rasheed et al. [26] who detected $S$. pneumoniae at rates of $17.8 \%$ and $30 \%$, respectively. This diversity may be related to patient immunity, infection dose, seasonal variation, food intake, or antibiotic therapy [27].
Young and elderly patients were found to be highly susceptible to infection. S. pyogenes and S. pneumoniae were also reported in most patients with chronic disease, especially diabetes mellitus (Table-2). The majority of patients had been infected several times, especially in the case of $S$. pyogenes, indicating the presence of antimicrobial resistance. Although tonsillitis and pharyngitis are caused by different microorganisms, the presence of resistant strains of streptococci among patients is an important indication that they are the causative agent.

Using specific primers for discrimination between Streptococcus species is important for

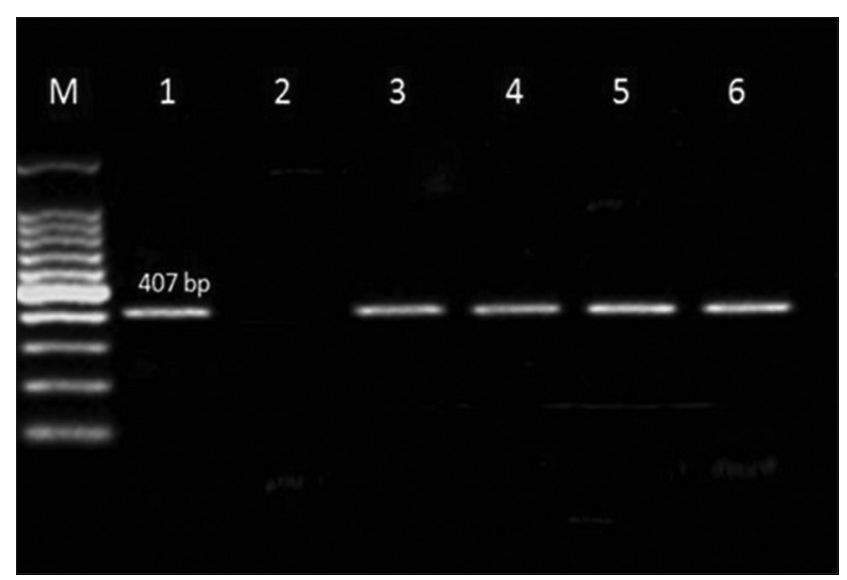

Figure-1: Polymerase chain reaction result of spy 1258 gene specific for Streptococcus pyogenes in human and meat products samples. Lane 1: Control positive, Lane 2: Control negative, Lanes 3, 4, 5, and 6: Positive.

Table-3: Incidence of Streptococcus species in meat products samples.

\begin{tabular}{|c|c|c|c|c|c|c|c|c|c|}
\hline \multirow[t]{2}{*}{ Samples } & \multirow[t]{2}{*}{$\begin{array}{l}\text { No. of examined } \\
\text { samples }\end{array}$} & \multicolumn{2}{|c|}{$\begin{array}{c}\text { Streptococcus } \\
\text { pyogenes }\end{array}$} & \multicolumn{2}{|c|}{$\begin{array}{c}\text { Streptococcus } \\
\text { mitis }\end{array}$} & \multicolumn{2}{|c|}{$\begin{array}{c}\text { Streptococcus } \\
\text { pneumoniae }\end{array}$} & \multicolumn{2}{|c|}{ Total } \\
\hline & & $\mathbf{n}$ & $\%$ & $\mathbf{n}$ & $\%$ & $\mathbf{n}$ & $\%$ & $\mathbf{n}$ & $\%$ \\
\hline Beef luncheon & 50 & 6 & 12 & 4 & 8 & 3 & 6 & 13 & 26 \\
\hline Basterma & 50 & 2 & 4 & 2 & 4 & 2 & 4 & 6 & 12 \\
\hline Beef burger & 50 & 1 & 2 & 1 & 2 & 1 & 2 & 3 & 6 \\
\hline Beef kofta & 50 & 2 & 4 & 1 & 2 & 0 & 0 & 3 & 6 \\
\hline Total & 200 & 11 & 5.5 & 8 & 4 & 6 & 3 & 25 & 12.5 \\
\hline
\end{tabular}

Table-4: Antimicrobial resistance of the isolated Streptococcus strains from human and meat products samples.

\begin{tabular}{|c|c|c|c|c|c|c|c|c|c|c|c|c|}
\hline \multirow[t]{3}{*}{ Antimicrobial } & \multicolumn{4}{|c|}{ Streptococcus pyogenes } & \multicolumn{4}{|c|}{ Streptococcus mitis } & \multicolumn{4}{|c|}{ Streptococcus pneumoniae } \\
\hline & \multicolumn{2}{|c|}{$\begin{array}{c}\text { Human } \\
n=14\end{array}$} & \multicolumn{2}{|c|}{$\begin{array}{l}\text { Meat products } \\
\qquad n=11\end{array}$} & \multicolumn{2}{|c|}{$\begin{array}{c}\text { Human } \\
\mathbf{n}=9\end{array}$} & \multicolumn{2}{|c|}{$\begin{array}{l}\text { Meat products } \\
\qquad \mathbf{n}=\mathbf{8}\end{array}$} & \multicolumn{2}{|c|}{ Human $\mathbf{n = 7}$} & \multicolumn{2}{|c|}{$\begin{array}{l}\text { Meat products } \\
n=6\end{array}$} \\
\hline & $\mathbf{n}$ & $\%$ & $\mathbf{n}$ & $\%$ & $\mathbf{n}$ & $\%$ & $\mathbf{n}$ & $\%$ & $\mathbf{n}$ & $\%$ & $\mathbf{n}$ & $\%$ \\
\hline DA & 9 & 64.3 & 3 & 27.3 & 5 & 55.6 & 2 & 25 & 4 & 57.1 & 3 & 50 \\
\hline AMC & 11 & 78.6 & 6 & 54.5 & 7 & 77.8 & 6 & 75 & 6 & 85.7 & 5 & 83.3 \\
\hline AMP & 9 & 64.3 & 9 & 81.8 & 6 & 66.6 & 5 & 62.5 & 5 & 71.4 & 4 & 66.7 \\
\hline CIP & 5 & 35.7 & 6 & 54.5 & 4 & 44.4 & 3 & 37.5 & 5 & 71.4 & 3 & 50 \\
\hline OFX & 6 & 42.9 & 2 & 18.2 & 3 & 33.3 & 1 & 12.5 & 4 & 57.1 & 2 & 33.3 \\
\hline CRO & 8 & 57.1 & 2 & 18.2 & 3 & 33.3 & 3 & 37.5 & 5 & 71.4 & 2 & 33.3 \\
\hline FOX & 7 & 50 & 3 & 27.3 & 5 & 55.6 & 3 & 37.5 & 3 & 42.9 & 3 & 50 \\
\hline $\mathrm{S}$ & 3 & 21.4 & 1 & 9.1 & 2 & 22.2 & 2 & 25 & 4 & 57.1 & 1 & 16.7 \\
\hline AK & 4 & 28.6 & 3 & 27.3 & 5 & 55.6 & 4 & 50 & 2 & 28.6 & 3 & 50 \\
\hline TE & 12 & 85.7 & 9 & 81.8 & 8 & 88.9 & 7 & 87.5 & 6 & 85.7 & 4 & 66.7 \\
\hline
\end{tabular}

$\mathrm{DA}=$ Clindamycin $10 \mu \mathrm{g}, \mathrm{AMC}=$ Amoxicillin/clavulanic acid $30 \mu \mathrm{g}, \mathrm{AMP}=$ Ampicillin $10 \mu \mathrm{g}, \mathrm{CIP}=$ Ciprofloxacin $5 \mu \mathrm{g}$,

OFX=Ofloxacin $5 \mu \mathrm{g}$. CRO=Ceftriaxone $30 \mu \mathrm{g}, \mathrm{FOX}=$ Cefoxitin $30 \mu \mathrm{g}, \mathrm{S}=$ Streptomycin $10 \mu \mathrm{g}, \mathrm{AK}=\mathrm{Amikacin} 30 \mu \mathrm{g}$, and $\mathrm{TE}=$ Tetracycline $30 \mu \mathrm{g}$ 
proper diagnosis and effective treatment. As discussed by Dunne et al. [22], spy1258 is a target gene for $S$. pyogenes only and has not been reported in other streptococci or any other bacteria. S. mitis and $S$. pneumoniae are closely related immunologically and biochemically, and misidentification can occur during routine microbiological examination. Therefore, specific genetic markers are needed to accurately differentiate between them: The pheA

Table-5: Effect of oregano oil nanoemulsion on Streptococcus isolates of human and meat products samples.

\begin{tabular}{lcccc}
\hline Concentration (\%) & \multicolumn{2}{c}{ Inhibition zone mm } & p-value \\
\cline { 2 - 4 } & \multicolumn{3}{c}{$\begin{array}{c}\text { Oregano oil } \\
\text { nanoemulsion }\end{array}$} & \\
\cline { 2 - 4 } & Min & Max & Mean \pm SdE & \\
\hline 0.5 & 11 & 19 & $14.84 \pm 0.309$ & 0.05 \\
1 & 22 & 34 & $30.07 \pm 0.425$ & \\
2 & 25 & 36 & $31.29 \pm 0.450$ & \\
3 & 30 & 39 & $36.45 \pm 0.302$ & \\
\hline
\end{tabular}

$\mathrm{SdE}=$ Standard error

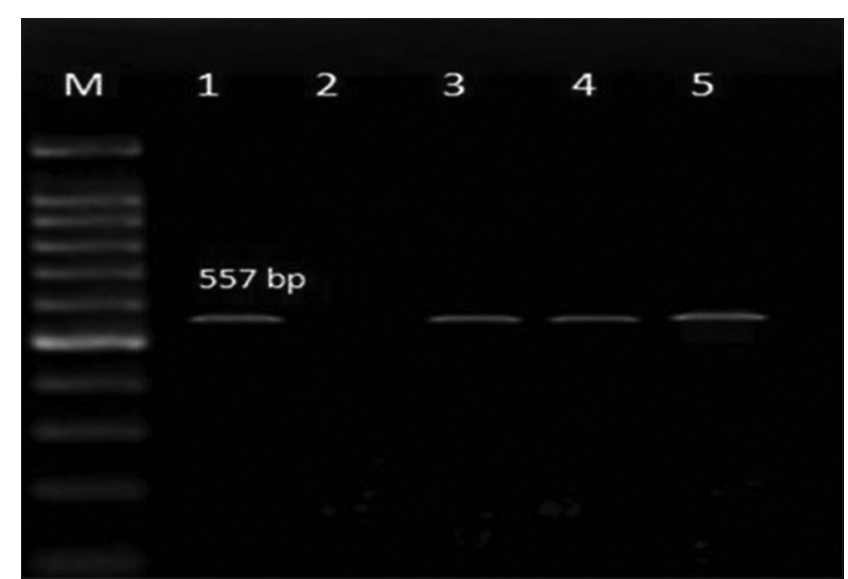

Figure-2: Polymerase chain reaction result of pheA gene specific for Streptococcus mitis in human and meat products samples. Lane 1: Control positive, Lane 2: Control negative, Lanes 3, 4, and 5: Positive.

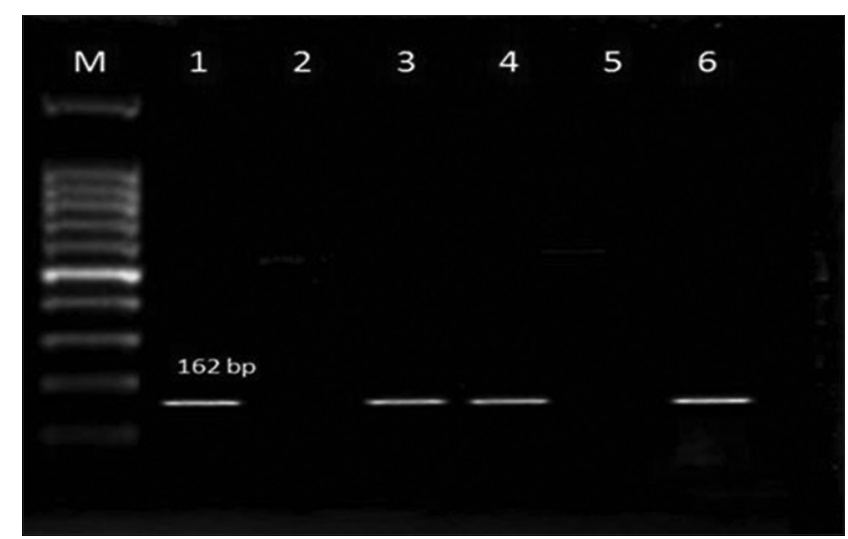

Figure-3: Polymerase chain reaction result of spn9802 gene specific for Streptococcus pneumoniae in human and meat products samples. Lane 1: Control positive, Lane 2: Control negative, Lanes 3, 4, and 6: Positive, Lane 5: Negative. gene is used for $S$. mitis and the spn9802 gene for $S$. pneumoniae $[10,18]$.

Respiratory droplets released during sneezing or coughing, and inoculation from the hands, are considered to be the most common routes of dissemination of Streptococcal pharyngitis. Therefore, the presence of human pathogens in meat products is an important indicator of contamination of food by food handlers, which may occur at any step during food processing and handling [28].

The results shown in Table- 3 indicate that beef luncheon had the highest microbial load of $26 \%$. Basterma samples harbored the three species of streptococci at a percentage of $12 \%$ ( $4 \%$ for each species). The lowest load was reported in beef burger and beef kofta, with a percentage of $6 \%$ for each, and S. pneumoniae could not be detected in beef kofta. Increased infection in luncheon and basterma may be related to the mishandling, because we observed that food handlers in food premises working without masks or gloves. Luncheon packages were exposed to food handlers several times during the day, which makes them susceptible to contamination, because this product is sold as slices cut on request. The meat is removed from refrigeration, sliced with a cutting machine, and then returned to the refrigerator. Nasal discharges from food handlers may contaminate surrounding environments and surfaces. Decreased contamination in beef burger and beef kofta may be attributed to the effects of freezing, because keeping products at $-20^{\circ} \mathrm{C}$ kills microorganisms [29].

The majority of $S$. pyogenes, $S$. mitis, and $S$. pneumoniae isolates from human and meat products exhibited resistance to various antimicrobials, especially tetracycline, ampicillin, and amoxicillin/ clavulanic acid (Table-4, Figure-4). These results indicated that these antimicrobials were widely used, in a haphazard manner, as a therapeutic medication, which is an important factor for the development of bacterial resistance, and prolongs the duration of recovery. The presence of resistant isolates in food products enables transmission of this resistance to consumers [30].

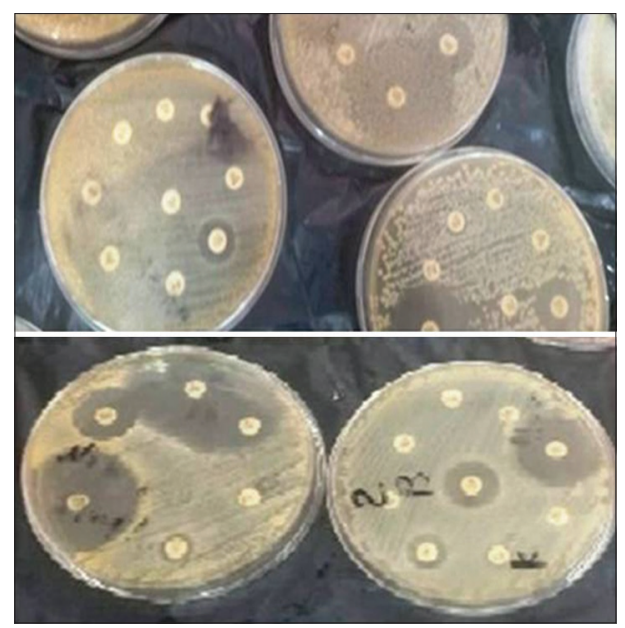

Figure-4: Antimicrobial sensitivity test for Streptococcus isolates of human and meat products samples. 
Therefore, new and natural antibacterial agents are needed to combat antimicrobial resistance in microorganisms. Such agents may include oregano essential oils, in which bacterial resistance was not observed to occur. ONE causes disturbances in membrane protein and lipid production, and defects in the intracellular osmotic pressure, bacterial cell wall and membrane damage, ATPase activity, and RNA synthesis [14]. Owing to the hydrophobic nature of essential oils, formulation of these oils as nanoemulsions will promotes their effects in food, because nanoemulsions are stable compounds, with large surface area and enhanced release inside the bacterial cell [31].

Some factors interfere with the inhibitory effect of essential oils in food, including the interaction between food ingredients and the essential oil, the type of food, the concentration of essential oil used, the origin of the essential oil (type of plant), and the method used for oil extraction [32]. In this context, nanoemulsions with a particle size of $20-200 \mathrm{~nm}$, have thermodynamic stability, coalescence, flocculation, and increased its distribution in food without adverse interactions with food components [33].

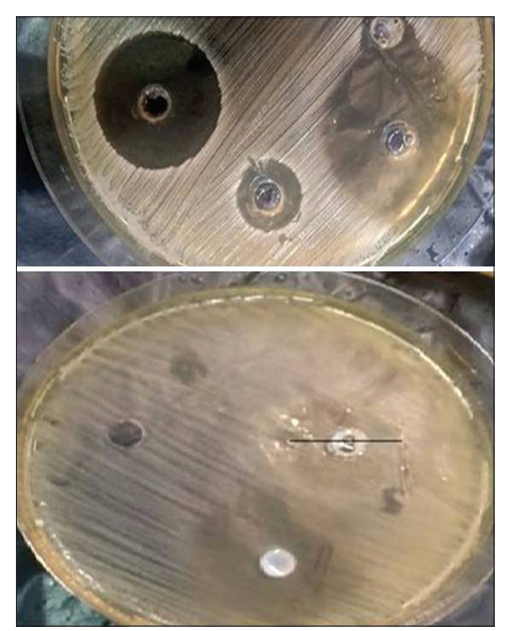

Figure-5: Antibacterial effect of oregano oil nanoemulsion on Streptococcus isolates of human and meat products samples.

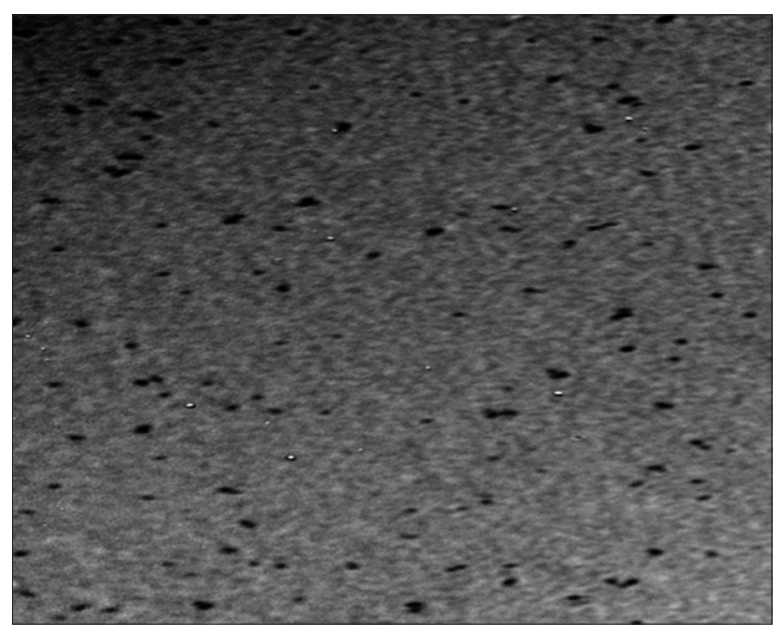

Figure-6: Transmission electron microscopy showing oregano oil nanoemulsion with average size $45.4 \mathrm{~nm}$.
The results of experiments using ONE against Streptococcus isolates from human and meat products are shown in Table-5 and Figure-5. ONE with an average particle size of $45.4 \mathrm{~nm}$ (Figure-6) at concentrations of $0.5 \%, 1.0 \%, 2.0 \%$, and $3.0 \%$ produced an inhibitory effect on the strains isolated, and increased concentrations had significantly increased effects $(p<0.05)$. These results indicated that ONE can be used against human pathogens and food contaminants, and may be favored by the public, due to its natural origin. It also has mucolytic, spasmolytic, cough smoothing, and anti-acne effects [34].

\section{Conclusion}

Effective diagnosis of $S$. pyogenes, $S$. mitis, and $S$. pneumoniae using specific primers and detection of their antimicrobial activity is necessary for disease treatment. Prevention of the transmission of these pathogens to food products through food handlers can be enhanced by health education and strict supervision, to control these zoonotic pathogens. The survival of these pathogens in food products should be further studied to identify the effective time and temperature of storage. ONE has an inhibitory effect on Streptococcal species isolated from human and food products. It can, therefore, be used as a human therapeutic and food preservative, but additional research is needed to identify the safe and effective dose.

\section{Authors' Contributions}

AAH and NMA equally contributed in the idea, study design, collection of samples and data, literature search, laboratory work, data analysis, and manuscript writing. Both authors read and approved the final manuscript.

\section{Acknowledgments}

We thank the medical team in Sohag University Hospital for their kind help. The authors did not receive any funds for this study.

\section{Competing Interests}

The authors declare that they have no competing interests.

\section{Publisher's Note}

Veterinary World (Publisher of International Journal of One Health) remains neutral with regard to jurisdictional claims in published institutional affiliation.

\section{References}

1. Daği, H., Yüksekkaya, S., Seyhan, T., Findik, D., Tuncer, I. and Arslan, U. (2018) Investigation of Streptococcus pyogenes virulence factors and typing by multiple locus variable number tandem repeat fingerprinting (MLVF) method. Mikrobiyol. Bull., 52(3): 233-246.

2. Lyytikäinen, O., Rautio, M., Carlson, P., Anttila, V., Vuento, R., Sarkkinen, H., Kostiala, A., Väisänen, M., Kanervo, A. and Ruutu, P. (2004) Nosocomial bloodstream infections due to Viridians streptococci in haematological 
and non-haematological patients: Species distribution and antimicrobial resistance. J. Antimicrob. Chemother., 53(4): 631-634.

3. Basaranoglu, S., Ozsurekci, Y., Aykac, K., Bicakcigil, A., Altun, B., Sancak, B., Cengiz, A., Kara, A. and Ceyhan, M. (2019) Streptococcus mitis/oralis causing blood stream infections in pediatric patients. Jpn. J. Infect. Dis., 72(1): 1-6.

4. Bogaert, D., De Groot, R. and Hermans, P. (2004) Streptococcus pneumoniae colonisation: The key to pneumococcal disease. Lancet Infect. Dis., 4(3): 144-154.

5. Almeida, S., Pedro, T., Paulo, C., De Lencastre, H. and Sá-Leão, R. (2020) Re-evaluation of Streptococcus pneumoniae carriage in Portuguese elderly by qPCR increases carriage estimates and unveils an expanded pool of serotypes. Sci. Rep., 10(1): 8373.

6. Beilharz, K., Nováková, L., Fadda, D., Branny, P., Massidda, O. and Veening, J. (2012) Control of cell division in Streptococcus pneumonia by the conserved Ser/Thr protein kinase StkP. Proc. Natl. Acad. Sci. U. S. A., 109(15): E905-E913.

7. Ingham, S., Wadhera, R., Chun-Him, C. and Devita, M. (2006) Survival of Streptococcus pyogenes on foods and food contact surfaces. J. Food Prot., 69(5): 1159-1163.

8. Liu, D., Hollingshead, S., Swiatlo, E., Lawrence, M. and Austin, W. (2005) Rapid identification of Streptococcus pyogenes with PCR primers from a putative transcriptional regulator gene. Res. Microbiol., 156(4): 564-567.

9. Richter, S., Heilmann, K., Dohrn, C., Riahi, F., Beekmann, S. and Doern, G. (2008) Accuracy of phenotypic methods for identification of Streptococcus pneumoniae isolates included in surveillance programs. J. Clin. Microbiol., 46(7): 2184-2188.

10. Park, H., Dang, H., Myung, S. and Kim, W. (2012) Identification of a pheA gene associated with Streptococcus mitis by using suppression subtractive hybridization. Appl. Environ. Microbiol., 78(8): 3004-3009.

11. Abdeldaima, G., Strålin, K., Olcén, P., Blomberg, J. and Hermann, B. (2008) Toward a quantitative DNA-based definition of Pneumococcal pneumonia: A comparison of Streptococcus pneumonia target genes, with special reference to the Spn9802 fragment. Diagn. Microbiol. Infect. Dis., 60(2): 143-150.

12. Oppegaard, O., Skrede, S., Mylvaganam, H. and Kittang, B. (2020) Emerging threat of antimicrobial resistance in $\beta$-hemolytic Streptococci. Front. Microbiol., 11: 797.

13. Dávila-Rodríguez, M., López-Malo, A., Palou, E., RamírezCorona, N. and Jiménez-Munguía, M. (2019) Antimicrobial activity of nanoemulsions of cinnamon, rosemary, and oregano essential oils on fresh celery. $L W T, 112(7): 108247$.

14. Lu, M., Dai, T., Murray, C. and Wu, M. (2018) Bactericidal property of Oregano oil against multidrug-resistant clinical isolates. Front. Microbiol., 9: 2329.

15. Okonko, I., Odu, N. and Igboh, I. (2013) Microbiological analysis of Kilishi sold in Port Harcourt, Nigeria. N. Y. Sci. J., 6(7): 37-43.

16. Quinn, P., Bryan, M., Carter, M. and Carter, G. (2013) Clinical Veterinary Microbiology. $2^{\text {nd }}$ ed. Mosby Ltd., United States. p327-344.

17. Degaim, Z., Taher, E. and Shallal, M. (2019) Molecular study of spy 1258 and smeZ genes in Group A Streptococcal tonsillitis. J. Pure Appl. Microbiol., 13(1): 433-439.

18. Suzuki, N., Yuyama, M., Maeda, S., Ogawa, H., Mashiko, K. and Kiyoura, Y. (2006) Genotypic identification of presumptive Streptococcus pneumoniae by PCR using four genes highly specific for S. pneumonia. J. Med. Microbiol.,
55(6): 709-714.

19. Clinical and Laboratory Standards Institute. (2013) Performance Standards for Antimicrobial Susceptibility Testing, Twenty Third Informational Supplements. Clinical and Laboratory Standards Institute, United States.

20. Bhargava, K., Conti, D., da Rocha, S. and Zhang, Y. (2015) Application of an oregano oil nanoemulsion to the control of foodborne bacteria on fresh lettuce. Food Microbiol., 47: 69-73.

21. Rajeshkumar, S. and Malarkodi, C. (2014) In vitro antibacterial activity and mechanism of silver nanoparticles against foodborne pathogens. Bioinorg. Chem. Appl., 2014: 581890 .

22. Dunne, E., Marshall, J., Baker, C., Manning, J., Gonis, G., Danchin, M., Smeesters, R., Satzke, C. and Steer, A. (2013) Detection of group A streptococcal pharyngitis by quantitative PCR. BMC Infect. Dis., 13: 312.

23. Al-Saadi, K.A., Naji, H.S., Al-Saadi, A.H. and Muhammed, A.H. (2015) Detection and identification of Streptococcus pyrogenes from ENT patients by different methods. J. Pharm. Biomed. Sci., 5(6): 480-486.

24. Khalaf, N., Najeeb, L. and Abdul-Jalil, A. (2020) Molecular study of spy1258 gene in Streptococcus pyogenes isolated from pharyngitis patients in Fallujah city. Medico Legal Update, 20(1): 585-590.

25. Thornton, H., Haya, A., Redmond, N., Turnbulla, S., Christensenc, H., Petersd, T., Leeminge, J., Loveringe, A., Vipondf, B., Muirf, P. and Blair, P. (2017) Throat swabs in children with respiratory tract infection: Associations with clinical presentation and potential targets for point-of-care testing. Fam. Pract., 34(4): 407-415.

26. Rasheed, R., Hasni, K., Taj, M., Shafi, M. and Rasheed, S. (2020) Isolation and biochemical characterization of Streptococus pneumoniae from throat swabs and sputum of children and adult in Quetta district. Pure Appl. Biol., 9(3): 1755-1762.

27. Azike, C., Agi, V. and Akere, B. (2019) The prevalence of Group A Streptococcus as a re-emerging microorganism in Port Harcourt Metropolis. IJPR, 2(3): 1-6.

28. Katzenell, U., Shemer, J. and Bar-Dayan, Y. (2011) Streptococcal contamination of food: An unusual cause of epidemic pharyngitis. Epidemiol. Infect. 127(2): 179-184.

29. Cota, A. and Alvim, R. (2018) Effect of storage temperature on Streptococcus mutans viability. Rev. Odontol. UNESP, 47(2): 74-78.

30. World Health Organization. (2017) Antimicrobial Resistance in the Food Chain. World Health Organization, Geneva. Available from: https://www.who.int/foodsafety/ areas_work/antimicrobial-resistance/amrfoodchain/en. Retrieved on 07-06-2021.

31. Aswathanarayan, J. and Vittal, R. (2019) Nanoemulsions and their potential applications in food industry. Front. Sustain. Food Syst., 3: 95.

32. Hyldgaard, M., Mygind, T. and Meyer, R. (2012) Essential oils in food preservation: Mode of action, synergies, and interactions with food matrix components. Front Microbiol., 3: 12.

33. Asensio, C., Quiroga, P., Al-Gburi, A., Huang, Q. and Grosso, N. (2020) Rheological behavior, antimicrobial and Quorum sensing inhibition study of an Argentinean oregano essential oil nanoemulsion. Front Nutr., 7: 569913.

34. Taleb, M., Abdeltawab, N., Shamma, R., Abdelgayed, S, Mohamed, S., Farag, M. and Ramadan, M. (2018) Origanum vulgare L. Essential oil as a potential anti-acne topical nanoemulsion-in vitro and in vivo study. Molecules, 23(9): 2164. 